\title{
White matter injury but not germinal matrix hemorrhage induces elevated osteopontin expression in human preterm brains
}

\author{
Gisela Nilsson ${ }^{1}$, Ana A. Baburamani ${ }^{2}$, Mary A. Rutherford², Changlian Zhu ${ }^{3,4}$, Carina Mallard ${ }^{1}$, Henrik Hagberg', \\ Regina Vontell ${ }^{2,6}$ and Xiaoyang Wang ${ }^{5^{*}}$ (D)
}

\begin{abstract}
Osteopontin (OPN) is a matricellular protein that mediates various physiological functions and is implicated in neuroinflammation, myelination, and perinatal brain injury. However, its expression in association with brain injury in preterm infants is unexplored. Here we examined the expression of OPN in postmortem brains of preterm infants and explored how this expression is affected in brain injury. We analyzed brain sections from cases with white matter injury (WMI) and cases with germinal matrix hemorrhage $(\mathrm{GMH})$ and compared them to control cases having no brain injury. WMI cases displayed moderate to severe tissue injury in the periventricular and deep white matter that was accompanied by an increase of microglia with amoeboid morphology. Apart from visible hemorrhage in the germinal matrix, GMH cases displayed diffuse white matter injury in the periventricular and deep white matter. In non-injured preterm brains, OPN was expressed at low levels in microglia, astrocytes, and oligodendrocytes. OPN expression was significantly increased in regions with white matter injury in both WMI cases and GMH cases. The main cellular source of OPN in white matter injury areas was amoeboid microglia, although a significant increase was also observed in astrocytes in WMI cases. OPN was not expressed in the germinal matrix of any case, regardless of whether there was hemorrhage. In conclusion, preterm brain injury induces elevated OPN expression in microglia and astrocytes, and this increase is found in sites closely related to injury in the white matter regions but not with the hemorrhage site in the germinal matrix. Thus, it appears that OPN takes part in the inflammatory process in white matter injury in preterm infants, and these findings facilitate our understanding of OPN's role under both physiological and pathological conditions in the human brain that may lead to greater elucidation of disease mechanisms and potentially better treatment strategies.
\end{abstract}

Keywords: Osteopontin, Preterm, Postmortem brain, Microglia, White matter, Hemorrhage

\section{Introduction}

Preterm infants born before 32 weeks' gestation or with a birth weight less than $1,500 \mathrm{~g}$ are frequently affected by brain injuries that are associated with long-term neurological complications such as cerebral palsy, vision loss,

\footnotetext{
${ }^{*}$ Correspondence: xiaoyang.wang@fysiologi.gu.se

${ }^{5}$ Centre of Perinatal Medicine and Health, Institute of Clinical Sciences,

Department of Obstetrics and Gynecology, Sahlgrenska Academy, Gothenburg University, 40530 Gothenburg, Sweden

Full list of author information is available at the end of the article
}

hearing problems, impaired learning, and behavioral and psychological problems [35, 61]. The major types of brain injury affecting preterm infants are white matter injury and germinal matrix-intraventricular hemorrhage (GMH-IVH) $[9,67]$.

Injury affecting the white matter adjacent to the cerebral ventricles, referred to as periventricular white matter injury (PVWMI), is the most common form of white matter injury in preterm infants and is caused by developmental immaturity, infection, and hypoxia/ original author(s) and the source, provide a link to the Creative Commons licence, and indicate if changes were made. The images or other third party material in this article are included in the article's Creative Commons licence, unless indicated otherwise in a credit line to the material. If material is not included in the article's Creative Commons licence and your intended use is not permitted by statutory regulation or exceeds the permitted use, you will need to obtain permission directly from the copyright holder. To view a copy of this licence, visit http://creativecommons.org/licenses/by/4.0/. The Creative Commons Public Domain Dedication waiver (http://creativeco mmons.org/publicdomain/zero/1.0/) applies to the data made available in this article, unless otherwise stated in a credit line to the data. 
ischemia. These insults induce cell death, excitotoxicity, free-radical accumulation, energy failure, and inflammation that lead to brain lesions with focal necrosis involving reactive astrogliosis and microglia activation as well as to a decrease in pre-myelinating oligodendrocytes [72, 74]. PVWMI can be diffusely apparent or more severe, involving cyst formation. On diagnostic magnetic resonance imaging scans, WMI is visualized as either discrete focal or more diffuse areas of magnetic resonance signal abnormalities $[19,30,42]$. The white matter in premature infants is rich in oligodendrocyte progenitors and premyelinating oligodendrocytes that are vulnerable to excitotoxicity, oxidative stress, and inflammation, all of which can lead to oligodendrocyte developmental arrest and disrupted myelination and white matter injury $[6,24,46]$.

GMH-IVH is a consequence of the fragile vascular network of the germinal matrix and immature cerebral autoregulation $[8,9]$. GMH usually develops between the thalamus and the caudate, affecting the highly vascularized subependymal germinal matrix area, and if large it can rupture into the ventricles (IVH) [47]. GMH results in pressure on surrounding tissue, partial secondary ischemia, blood clot formation, and disruption of cerebrospinal fluid circulation, all of which can contribute to secondary injury. In addition, GMH-IVH can further trigger microglia activation, reactive astrogliosis, and inflammatory responses $[7,32,38]$ in adjacent white matter also contributing to white matter injury $[9,37,62]$.

Osteopontin (OPN) is a multifunctional extracellular matrix glycoprotein and cytokine that is involved in many physiological and pathological processes, including cell signaling, tissue repair, bone formation, immunity, and inflammation $[13,20]$. The many functions of OPN may reflect its multiple variants arising from transcriptional, posttranscriptional, and posttranslational modifications as well as the diversity of cell types that OPN interacts with. Under physiological conditions, the expression of OPN in various organs is low but its expression can be upregulated in response to injury or inflammation [70]. In the central nervous system (CNS), OPN exerts neuroprotective functions $[14,45]$ and can have detrimental effects in neuroinflammation [14, 69]. OPN has been shown to act as a chemoattractant for microglia, macrophages, and astrocytes during glial scar formation after ischemic injury in adult rodent models [21] and to play a role in neurodegeneration and demyelination diseases such as multiple sclerosis $[12,15,18,44,76]$ as well as in re-myelination [55]. Increased levels of OPN transcripts were reported in the brain tissue of multiple sclerosis patients [15]. In the immature brain, OPN is one of the most highly regulated molecules in perinatal brain injury $[26,68]$, where a neuroprotective role has been suggested in neonatal brain injury in rodent models equivalent to term infants $[16,68]$, while in younger mouse brains administration of OPN peptides exacerbated brain injury in a mouse model of hypoxia-ischemia-induced preterm brain injury [1]. In human infants, strong OPN immunoreactivity was detected in injured axons at the periphery of the ischemic zone in periventricular leukomalacia lesions in the subacute and chronic stages [65]. However, the expression and cellular source of OPN in human preterm infants, and its relation to brain injury, remains largely unknown. The aim of the present study was to explore the expression pattern of OPN in postmortem preterm infant brains and how it is affected in white matter injury and GMH.

\section{Material and methods}

\section{Human postmortem brains}

Written informed parental consent was acquired in accordance with the National Health Services (NHS) UK guidelines, and ethical approval was obtained from the National Research Ethics Services (West London), UK (ethic number: 07/H0707/139).

A total of 21 preterm postmortem brains at postmenstrual age 22-32 weeks from vaginally delivered infants were included in this study. Brain tissue blocks from these cases had a postmenstrual age calculated by gestational age (at delivery) plus age at death. No cases had known genetic mutations or diagnoses. Amniotic fluid infections were identified in 10/21 cases; however, no cases had identifiable vascular thrombosis or leptomeningitis. All brains were assessed macroscopically and microscopically at the time of clinical postmortem examination. Neuropathology and primary cause of death of the cases were evaluated by a perinatal pathologist. The causes of death were complications due to preterm birth/ extreme prematurity such as pneumonia and congestive heart failure, and these were similar for all three groups of infants. The details of each case, including the neuropathological findings and clinical information, are summarized in Table 1.

\section{Tissue preparation}

Following postmortem examinations, whole brains were fixed with $4 \%$ formalin for 5-7 weeks depending on their size. The whole brains were sliced by a pathologist, and tissue blocks were processed on a Bright Tissue Processor (Bright Instrument Co. Ltd.). Paraffin-embedded tissue blocks of the frontal lobe at the level of the caudate (i.e., anterior to Ammon's horn) were sectioned coronally at $6 \mu \mathrm{m}$ using a Leica RM2245 microtome (Leica Microsystems Ltd.) on super frost plus slides (Thermo Fisher, UK) [62, 73]. One section per case was used for routine hematoxylin and eosin (H\&E) staining to assess the gross neuropathology. Adjacent sections were then 


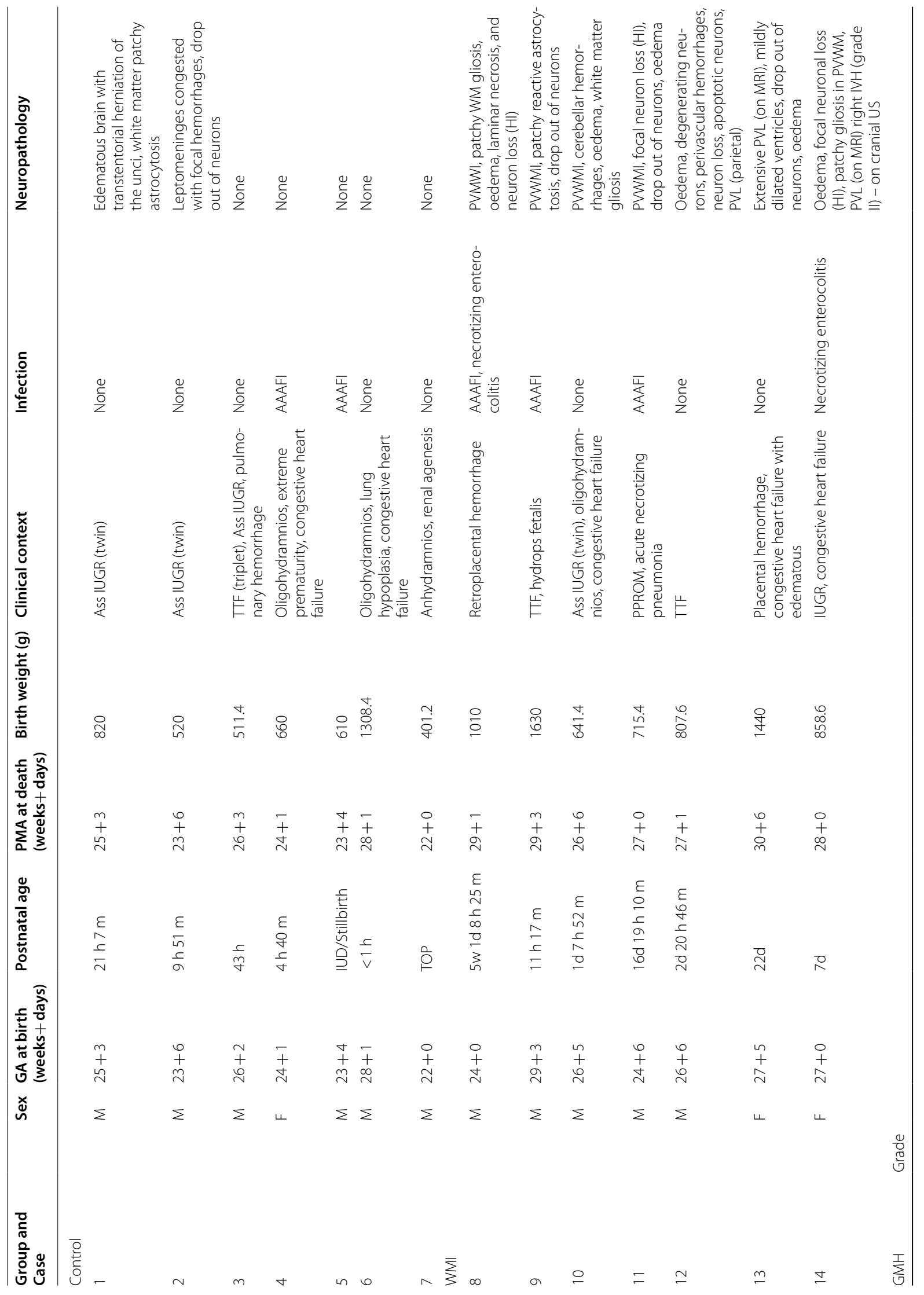




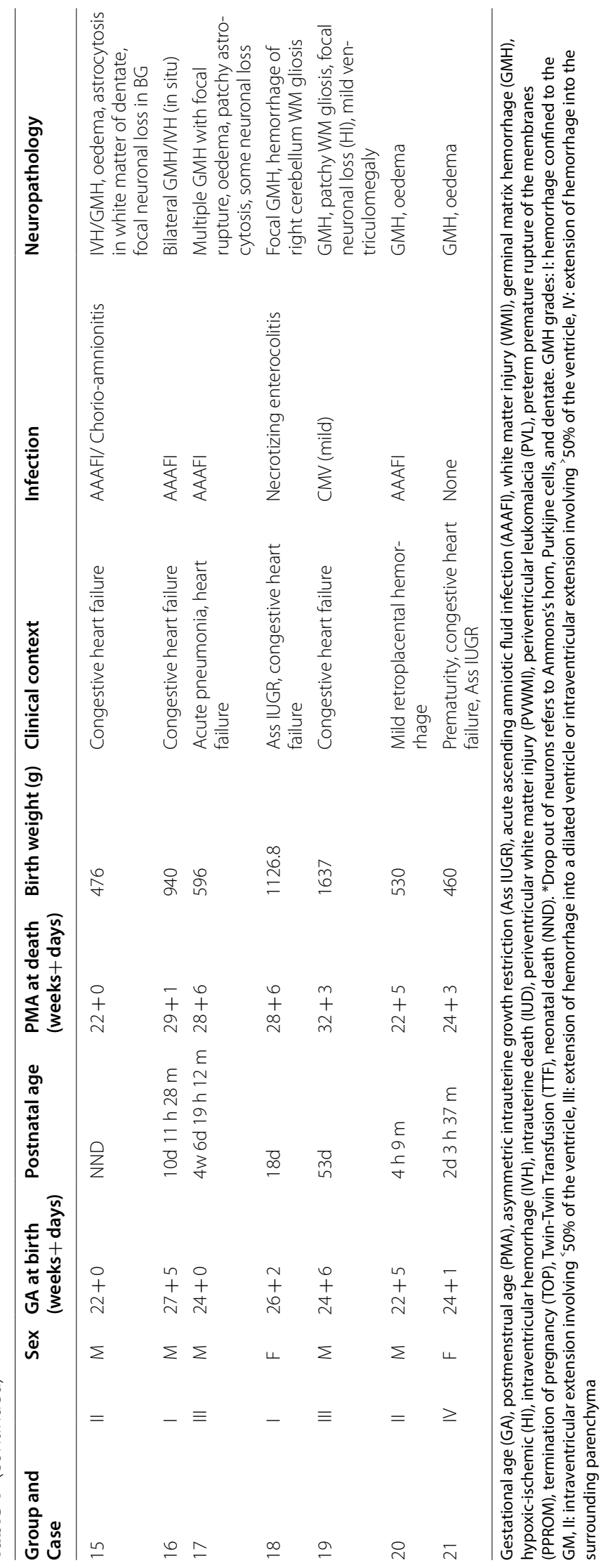


used for immunohistochemical and immunofluorescent staining.

\section{Immunohistochemistry and immunofluorescent staining} As previously described [73] human postmortem sections underwent routine paraffin removal and rehydration, were immersed in preheated $10 \mathrm{mM}$ citric acid $(\mathrm{pH}$ 6.0) with $0.1 \%$ Tween-20 (VWR International Ltd.) for $30 \mathrm{~min}$, and were cooled to room temperature for $20 \mathrm{~min}$. Slides were washed with phosphate-buffered saline (PBS; $\mathrm{pH}$ 7.4) and placed in $3 \%$ hydrogen peroxide to quench endogenous peroxidase activity. Sections were blocked with $5 \%$ fetal bovine serum, and primary antibodies were incubated overnight at $4{ }^{\circ} \mathrm{C}$. Details of the primary antibodies are given in Table 2 .

For immunohistochemical staining of OPN on the following day, sections were incubated with biotinylated horse anti-mouse secondary antibodies (1:200, Vector Laboratories) for $1 \mathrm{~h}$ at room temperature, washed with $\mathrm{PBS}$, and then incubated for $1 \mathrm{~h}$ with avidin-biotin complex (ABC, 1:200, Vector Laboratories, UK). The reactions were visualized with 3,3'-diamino-benzidine (DAB; Thermo Fisher Scientific, UK) for $10 \mathrm{~min}$. Sections were then dehydrated, cleared in xylene, and cover slipped.

For calculation of the number of OPN-positive cells, we used a light microscope (Olympus, BX56) modified for stereology with a motorized stage (H1P4BX ProScan stage with V31XYZE ProScan III Controller) with newCAST software (Visiopharm, Hørsholm, Denmark). Delineation of the region of interest (ROI) was performed using a $1.25 \times$ objective lens. Frames were randomly arranged within the ROI by the software using a $20 \times$ objective lens covering $15 \%$ of the ROI, and the images of the frames were used to calculate the number of cells using Fiji ImageJ.
For immunofluorescent staining (OPN-Iba1, OPNGFAP, and OPN-Olig2), sections were prepared as described above, and the next day the sections were rinsed in PBS and then incubated in a secondary antibody cocktail (Table 2) for $2 \mathrm{~h}$ at room temperature. Sections were washed and then mounted using ProLong Gold with DAPI (Invitrogen) and cover slipped.

For cell density calculations, four images were acquired within the white matter injury region using a $20 \times$ objective lens on a Zeiss Axio Imager Z2 microscope, and the number of cells was counted using Fiji ImageJ.

\section{Statistics}

GraphPad Prism version 8.3.0 (GraphPad software, San Diego, CA, USA) was used to perform the statistical analyses. One-way ANOVA was used for all comparisons. The data are presented in bar graphs as the mean \pm SEM. $P<0.05$ was considered statistically significant.

\section{Results}

Characteristics of white matter injury

Three groups of preterm infants at postmenstrual age 22-32 weeks were included in this study, including 7 control cases, 7 WMI cases, and 7 GMH cases (Table 1). Brain sections at the level of the caudate (i.e., anterior to Ammon's horn) were stained with H\&E to assess the gross neuropathologies. Figure 1 shows an overview of a brain section where injury was assessed in different regions of the white matter; the periventricular white matter, the deep white matter, and the sub-cortical white matter. White matter regions with intact tissue structures were considered as having no WMI (Fig. 2A-B). Pyknotic cells were present in non-injured white matter as expected because apoptosis plays a role in normal development by regulating cell numbers [36]. However, white

Table 2 Primary and secondary antibody information

\begin{tabular}{|c|c|c|c|c|c|}
\hline Antigen & Catalogue Number & Source & Species & Dilution [ab conc.] & Target \\
\hline Osteopontin (IgG2a) & ab69498 & Abcam & Mouse & $1: 750$ & Osteopontin \\
\hline GFAP $(\lg G 1)$ & G3893 & Sigma & Mouse & $1: 1000$ & Astrocytes, radial glia \\
\hline Olig2 & AB9610 & Millipore & Rabbit & $1: 500$ & Oligodendrocytes \\
\hline Iba1 & $019-19,741$ & WAKO & Rabbit & $1: 1000$ & Microglia \\
\hline Biotinylated secondary & BA-2001 & Vector Laboratories & Horse anti-mouse & $\begin{array}{l}1: 200 \\
{[1.5 \mathrm{mg} / \mathrm{ml}]}\end{array}$ & \\
\hline ABC Elite Kit & PK6200 & Vector Laboratories & & $1: 200$ & \\
\hline Alexa Fluor 488 & A21131 & Life Technologies & Goat anti-mouse (lgG2a) & $\begin{array}{l}1: 500 \\
{[2 \mathrm{mg} / \mathrm{ml}]}\end{array}$ & \\
\hline Alexa Fluor 546 & A21123 & Life Technologies & Goat anti-mouse (lgG1) & $\begin{array}{l}1: 500 \\
{[2 \mathrm{mg} / \mathrm{ml}]}\end{array}$ & \\
\hline Alexa Fluor 546 & A11010 & Life Technologies & Goat anti-rabbit (lgG) & $\begin{array}{l}1: 500 \\
{[2 \mathrm{mg} / \mathrm{ml}]}\end{array}$ & \\
\hline
\end{tabular}




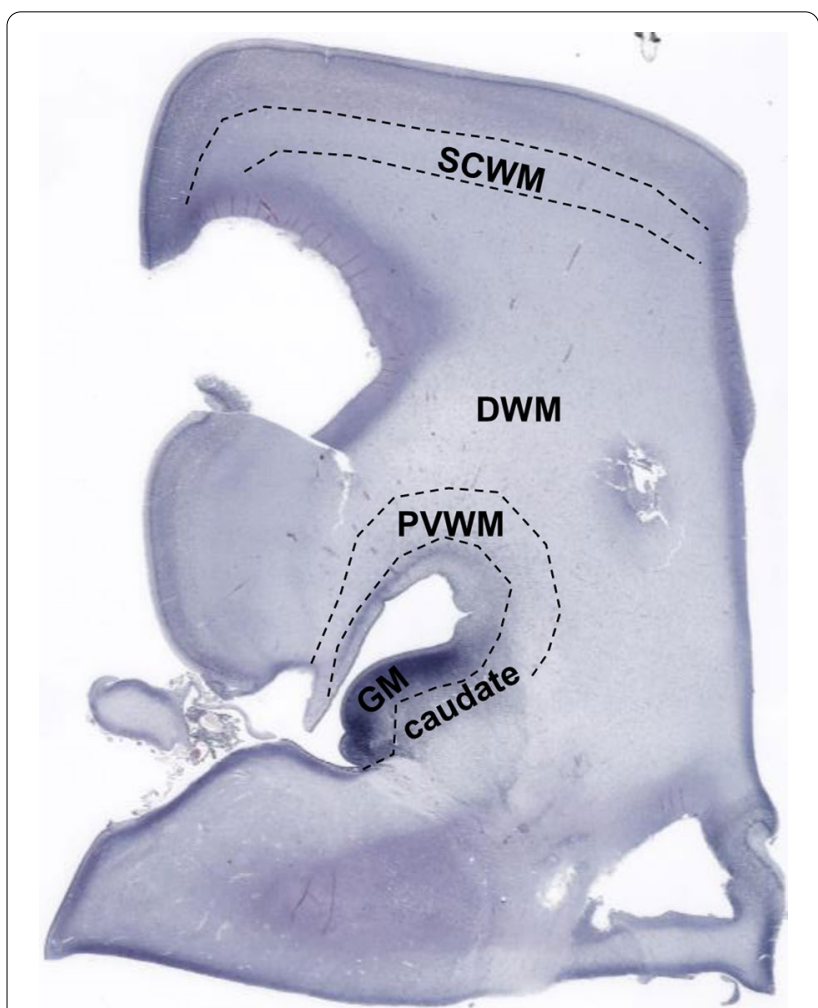

Fig. 1 Global view of an H\&E-stained coronal section anterior to Ammon's horn at $26+{ }^{6 / 7}$ weeks' postmenstrual age. SCWM; sub-cortical white matter, DMW; deep white matter, PVMl; periventricular white matter, GM; germinal matrix

matter regions with diffuse injury, i.e., disrupted tissue structures, were accompanied by an increase of pyknotic cells and hypercellularity (Fig. 2C-D). White matter regions with moderate injury showed patchy tissue loss and patches of pyknotic cells (Fig. 2E-F). In white matter regions with severe injury, extensive tissue loss was observed (Fig. 2G-H). In the WMI cases, the tissue damage was more pronounced in the periventricular white matter compared to the deep white matter. In the cases with moderate to severe periventricular WMI, the deep white matter also showed diffuse to moderate injury, sometimes extending to the sub-cortical white matter. In addition, GMH was accompanied by WMI in all GMH cases used in the current study, although to a lesser extent compared to WMI cases. WMI in GMH cases was also predominately located in the periventricular white matter, extending to the deep white matter and less so to the sub-cortical white matter.

\section{Characteristics of GMH}

Grade of hemorrhage in the GMH cases is shown in Table 1. We could observe the hemorrhage in the brain sections of 5 out of the 7 GMH cases used in this study.
In one of the cases without observed hemorrhage, only a small part of the germinal matrix was present in the section, while in the other case hemorrhage was observed in the periventricular white matter, but these cases were included in this group because hemorrhages were observable at post-mortem in brain sections not used in the current study. The extent of the hemorrhage observed in the sections ranged from small to large (Fig. 3). In 3 out of the 7 GMH cases, IVH was observed in the sections. In the germinal matrix, the hemorrhage was visible as dispersed (Fig. 3A-B) or as limited around ruptured vessels (Fig. 3C-D).

\section{Amoeboid microglia are increased in WMI}

The typical morphology of microglia in resting condition is ramified with many fine short processes for sensing their surroundings. During development and in response to injury, they take on an amoeboid morphology with rounded cell bodies and little or no processes, and this leads to increased phagocytic capability and increased motility [11]. We examined the cell density and morphology of microglia using the microglia marker ionized calcium-binding adapter molecule 1 (Iba1), a marker for ramified, intermediate, and amoeboid/activated microglia $[33,62,66,71]$.

In control cases, microglia were numerous in the germinal matrix and exhibited an amoeboid morphology (Fig. 4A-B), and this was also true for the WMI and GMH cases. In non-injured white matter, the microglia displayed a ramified morphology with extensive complex branching (Fig. 4C-F), while the microglia showed an amoeboid morphology with round to amorphous structures with a variety of short pseudopodia in WMI cases (Fig. 4G-H) and an intermediate or ramified morphology in the GMH cases (Fig. 4I-J). Comparing the numbers of microglia in the white matter injury regions, we did not find a significant difference in the numbers of Iba1positive cells between the three groups (Fig. 4K). Nevertheless, an increase in microglia numbers was found in 5 out of the 7 WMI cases. However, there was a significant increase in the number of Iba1-positive cells having an amoeboid morphology in the WMI cases compared to the control cases that was not observed in the GMH cases (Fig. 4L), suggesting that the microglial morphological state is related to the severity of the WMI.

\section{Astrocytes are altered in WMI}

Astrocytes react to WMI and undergo morphological, molecular, and functional changes through reactive astrogliosis [5, 59]. For examination of the numbers and morphology of astrocytes, we used the astrocyte marker glial fibrillary acidic protein (GFAP). In non-injured tissue, GFAP-positive astrocytes were most abundant in 

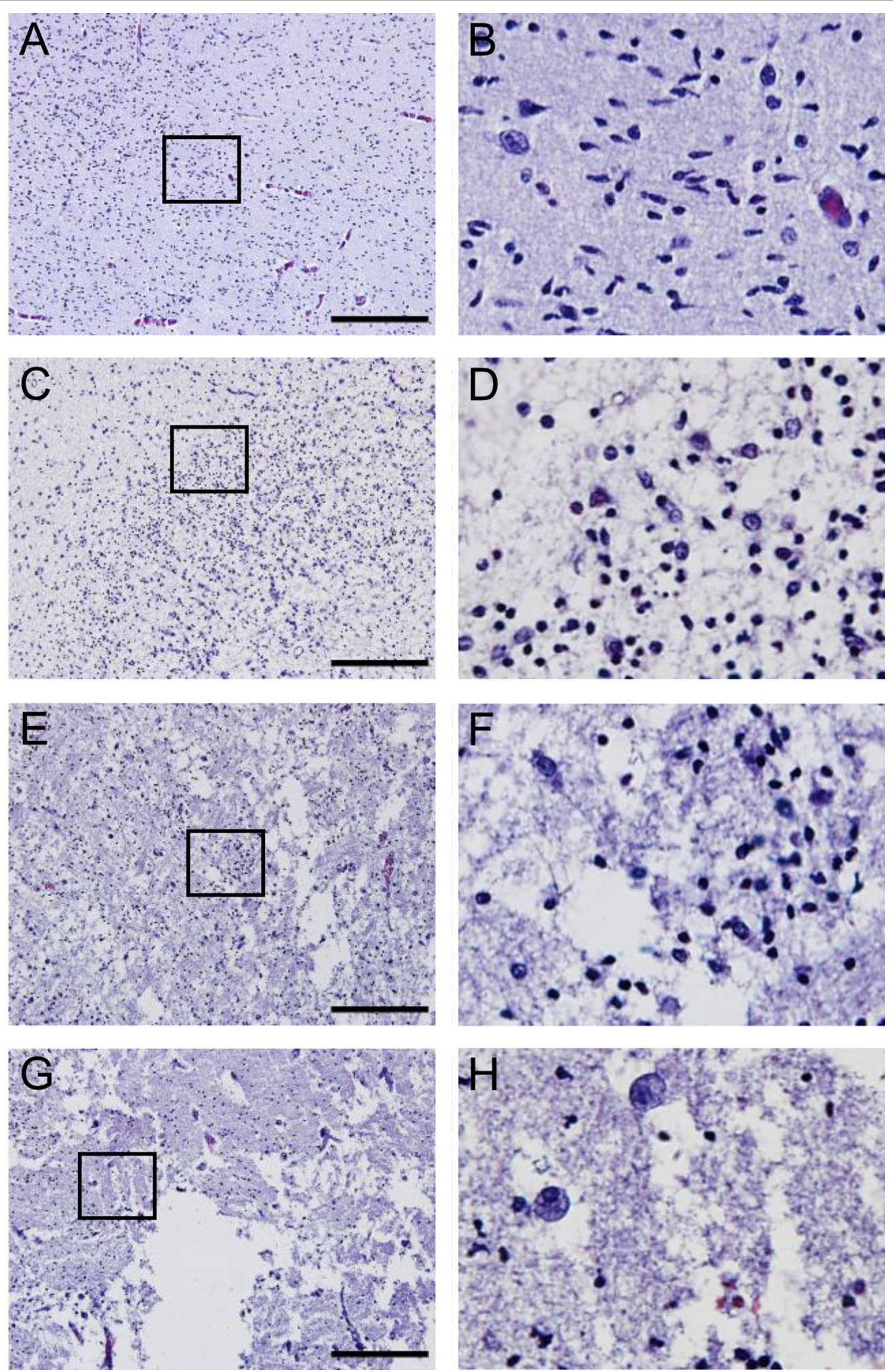

Fig. 2 The degree of WMI assessed in H\&E-stained sections. Representative images of white matter with no detectable injury (A-B), diffuse injury displaying disrupted tissue structures, hypercellularity, and pyknotic cells (C-D), moderate injury with patchy tissue loss and patches of pyknotic cells $(\mathbf{E}-\mathbf{F})$, or severe injury with extensive tissue loss $(\mathbf{G}-\mathbf{H})$. Right panel: magnification of the selected area. Scale bar $=200 \mu \mathrm{m}$ 

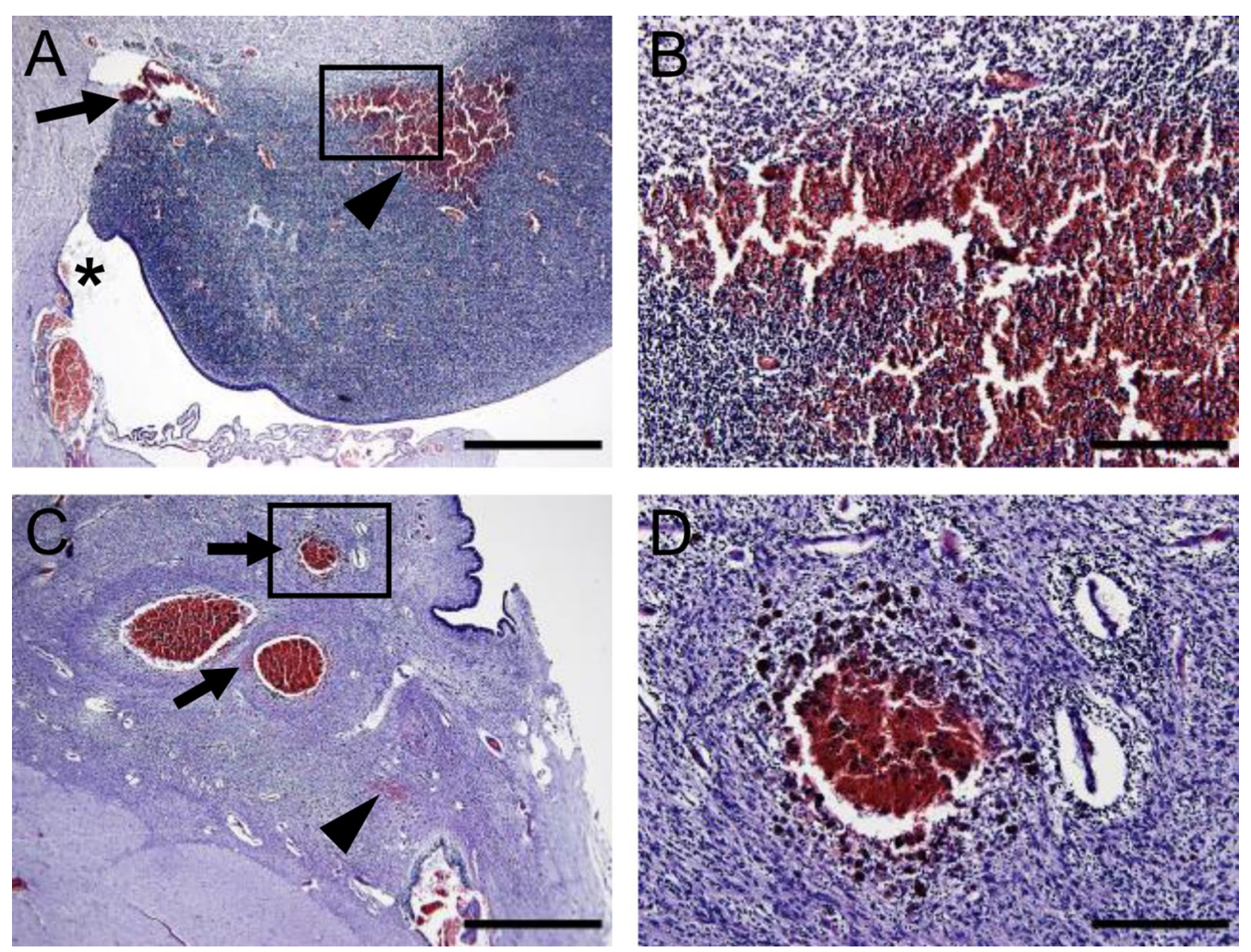

Fig. 3 Hemorrhage in the germinal matrix as observed in H\&E-stained sections. A-B GMH in a case at postmenstrual age $22+{ }^{5 / 7}$ weeks detected as dispersed (arrowhead) or limited around vessels (arrow) as well as apparent in the ventricle (star). C-D In a GMH case at postmenstrual age $32+{ }^{3 / 7}$ weeks the hemorrhage was mainly detected around ruptured vessels and contained aggregates (arrow), but small, dispersed bleedings (arrowhead) were also noticeable. Scale bars: $(\mathbf{A}$ and $\mathbf{C})=1 \mathrm{~mm},(\mathbf{B}$ and $\mathbf{D})=200 \mu \mathrm{m}$

the germinal matrix, exhibiting a fibrous and superficial morphology (Fig. 4M-N), and they were observed in periventricular crossroads and around blood vessels. GFAP-positive astrocytes were less abundant in white matter where they had a stellate morphology (Fig. 4O-P). In WMI and GMH cases, GFAP-positive astrocytes in the white matter displayed a morphology indicating varying degrees of reactivity, with elaborated processes and extended cell bodies (Fig. 4S-V). This was most obvious in regions close to the injury. However, there was no significant difference in overall cell numbers between the groups (Fig. 4W), although cases with moderate to severe
WMI showed increased astrocyte numbers (data not shown).

\section{Increased OPN expression is found in WMI regions}

To investigate the expression of OPN in the developing brain and in response to brain injury, parallel sections to the H\&E-stained sections were stained for OPN. Overall, the expression of OPN in the control cases was low in white matter regions, including the periventricular white matter, deep white matter, and sub-cortical white matter. In WMI cases, OPN-positive cells were found mainly in the white matter in association with injury,

(See figure on next page.)

Fig. 4 Microglia and astrocytes are altered in WMI. (A-J) Iba1 immunostaining (red) and nuclear counterstaining with DAPI was performed. (A-C) Examples demonstrating the distribution and morphology of microglia in the germinal matrix (A-B) and in the white matter (C-D) in non-injured tissue. (E-J) Representative immunofluorescence images demonstrating microglia in white matter having ramified morphology in control, amoeboid morphology in WMI, and ramified to intermediate morphology in GMH. (K) The numbers of Iba ${ }^{+}$cells in the white matter. (L) The numbers of amoeboid Iba ${ }^{+}$cells in the white matter. (M-V) Immunostaining with the astrocyte marker GFAP (red) and nuclear counterstaining with DAPI. (M-P) Images showing the distribution and morphology of astrocytes in non-injured tissue in the germinal matrix (M-N) and white matter (O-P). (Q-V) Representative images showing GFAP' astrocytes in the white matter having stellate morphology in controls, while having different degrees of reactive morphology in WMI and GMH. (W) The numbers of GFAP ${ }^{+}$cells in the white matter. Scale bars: $(\mathbf{A}$ and $\mathbf{C})=200 \mu \mathrm{m},(\mathbf{B}$ and $\mathbf{D})=25 \mu \mathrm{m},(\mathbf{E}, \mathbf{G}$, and $\mathbf{I})=50 \mu \mathrm{m},(\mathbf{F}, \mathbf{H}$, and $\mathbf{J})=25 \mu \mathrm{m},(\mathbf{M}$ and $\mathbf{O})=200 \mu \mathrm{m},(\mathbf{N}$ and $\mathbf{P})=25 \mu \mathrm{m},(\mathbf{Q}, \mathbf{S}$, and $\mathbf{U})=50 \mu \mathrm{m},(\mathbf{R}, \mathbf{T}$, and $\mathbf{V})=25 \mu \mathrm{m}$ 


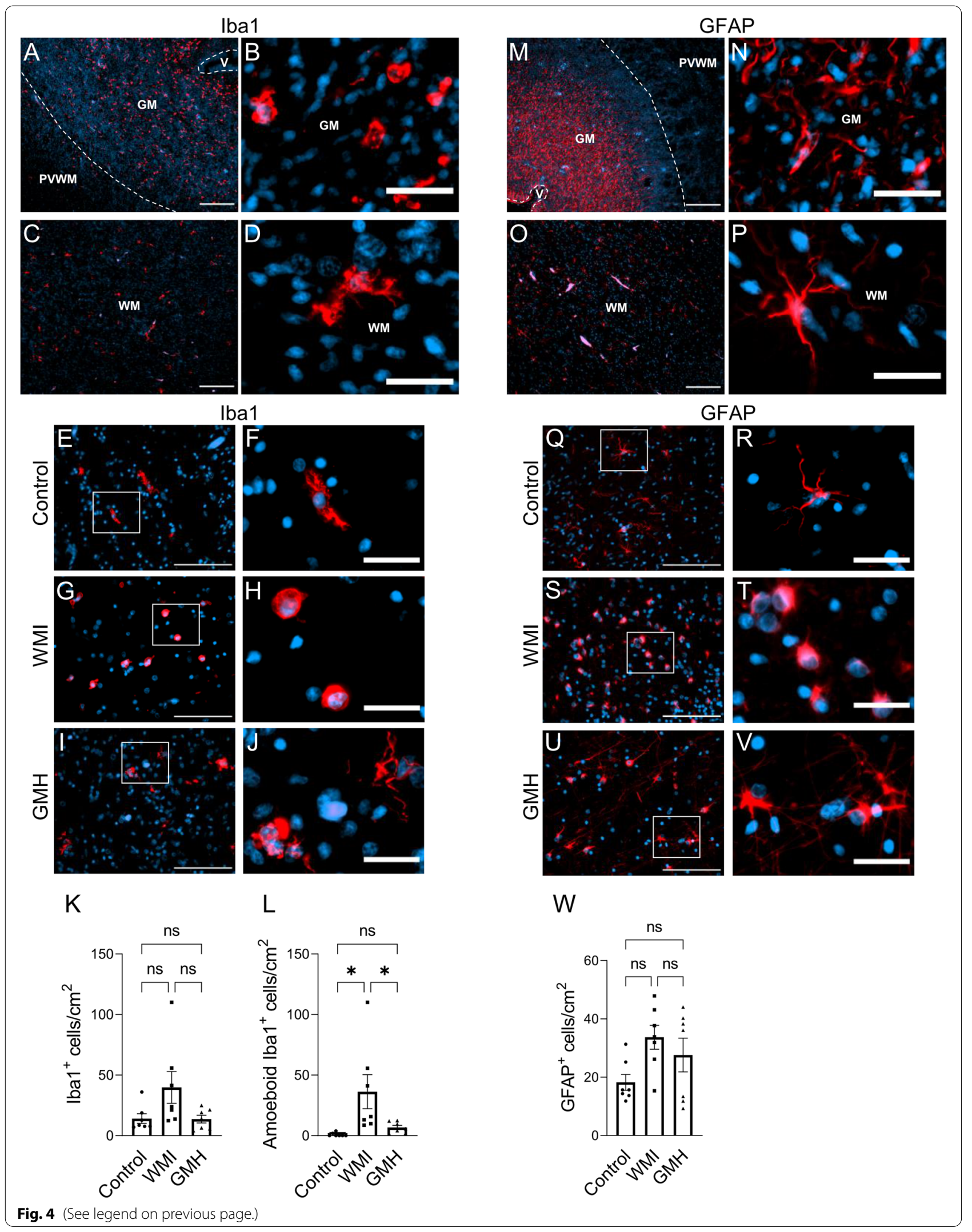


with more staining observed in regions with moderate to severe injury compared to diffusely injured white matter. OPN-positive cells were also found in regions with WMI in all but one of the GMH cases (Fig. 5A-F). There was a significant increase in OPN-positive cells in the regions of WMI in both the WMI $(\mathrm{p}=0.003)$ and GMH cases $(\mathrm{p}=0.017)$ compared to the corresponding white matter regions in control cases (Fig. 5G). This suggests that OPN expression in the white matter in the non-injured developing brain is low and that it is increased following WMI in preterm infants.
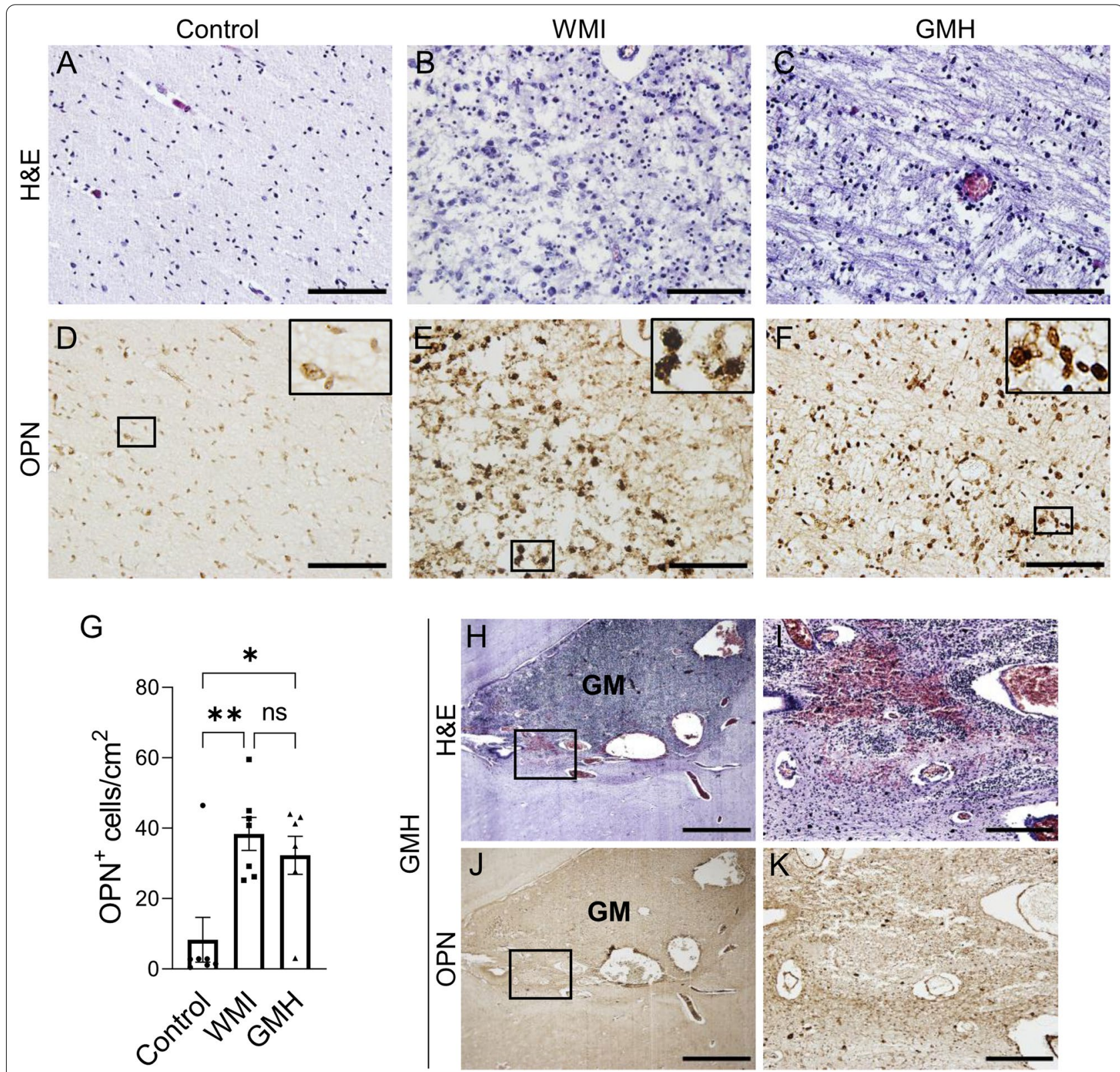

Fig. 5 OPN expression in the white matter and the germinal matrix. Parallel sections from a representative control, WMI, and GMH case stained with $\mathrm{H} \& \mathrm{E}(\mathbf{A}-\mathbf{C})$ or OPN-DAB (D-F) demonstrating tissue structure and OPN ${ }^{+}$cells in regions with white matter injury. (G) The numbers of OPN ${ }^{+}$ cells in the white matter. (H and $\mathbf{J})$ Parallel sections from a GMH case at postmenstrual age $28+{ }^{6 / 7}$ weeks stained with H\&E or OPN-DAB. Scale bars: $(\mathbf{A}-\mathbf{F})=200 \mu \mathrm{m},(\mathbf{H}$ and $\mathbf{J})=1 \mathrm{~mm}$, and $(\mathbf{I}$ and $\mathbf{K})=200 \mu \mathrm{m}$ 


\section{OPN expression is not elevated in regions of germinal matrix hemorrhage}

OPN expression has been shown to be associated with different kinds of injury, and we next investigated if OPN expression is also elevated in association with hemorrhage regions as was found in WMI. OPN staining was negative in the germinal matrix in all control and WMI cases. Only very few OPN-positive cells were found in the germinal matrix following hemorrhage in the GMH group (Fig. 5H-K), suggesting that OPN expression is not induced in association with the hemorrhage sites.

\section{Elevated OPN expression is induced in microglia and astrocytes, but not in oligodendrocytes}

To identify the cellular source of OPN in the preterm infant brains, we first examined the expression of OPN in the control cases using double fluorescent immunostaining of OPN together with Iba1 (microglia), GFAP (astrocytes), and the oligodendrocyte-specific marker Olig2, respectively. We found that OPN in white matter was co-expressed with all three cell types examined, namely microglia, astrocytes, and oligodendrocytes, although the expression level was low.
OPN was found to be secreted by macrophages and microglia to modulate the inflammatory responses to different brain injuries $[48,53,57,64]$, and upregulation of OPN in reactive astrocytes has also been described [28, 29]. We found that in regions with injured white matter there was a significant increase in the numbers of microglia expressing OPN in the WMI cases compared to the control cases $(p=0.005)$ (Fig. 6A-H and M), while there was no significant increase in the numbers of OPNexpressing microglia associated with WMI regions in the GMH group compared to controls. However, microglia exhibiting ramified to amoeboid morphology in GMH cases expressed OPN (Fig. 6I-L and M). Similarly, in the white matter regions there was a significant increase in the numbers of astrocytes expressing OPN in WMI cases $(p=0.024)$, but not in GMH cases, compared to the control group (Fig. 7A-M). Furthermore, Olig2-positive oligodendrocytes co-expressed OPN but the number of OPN-positive oligodendrocytes in injured white matter did not change in WMI or GMH cases (Fig. 8A-M). This confirms that all three types of cells express OPN; however, OPN expression is increased in microglia and astrocytes but not in oligodendrocytes in response to WMI.

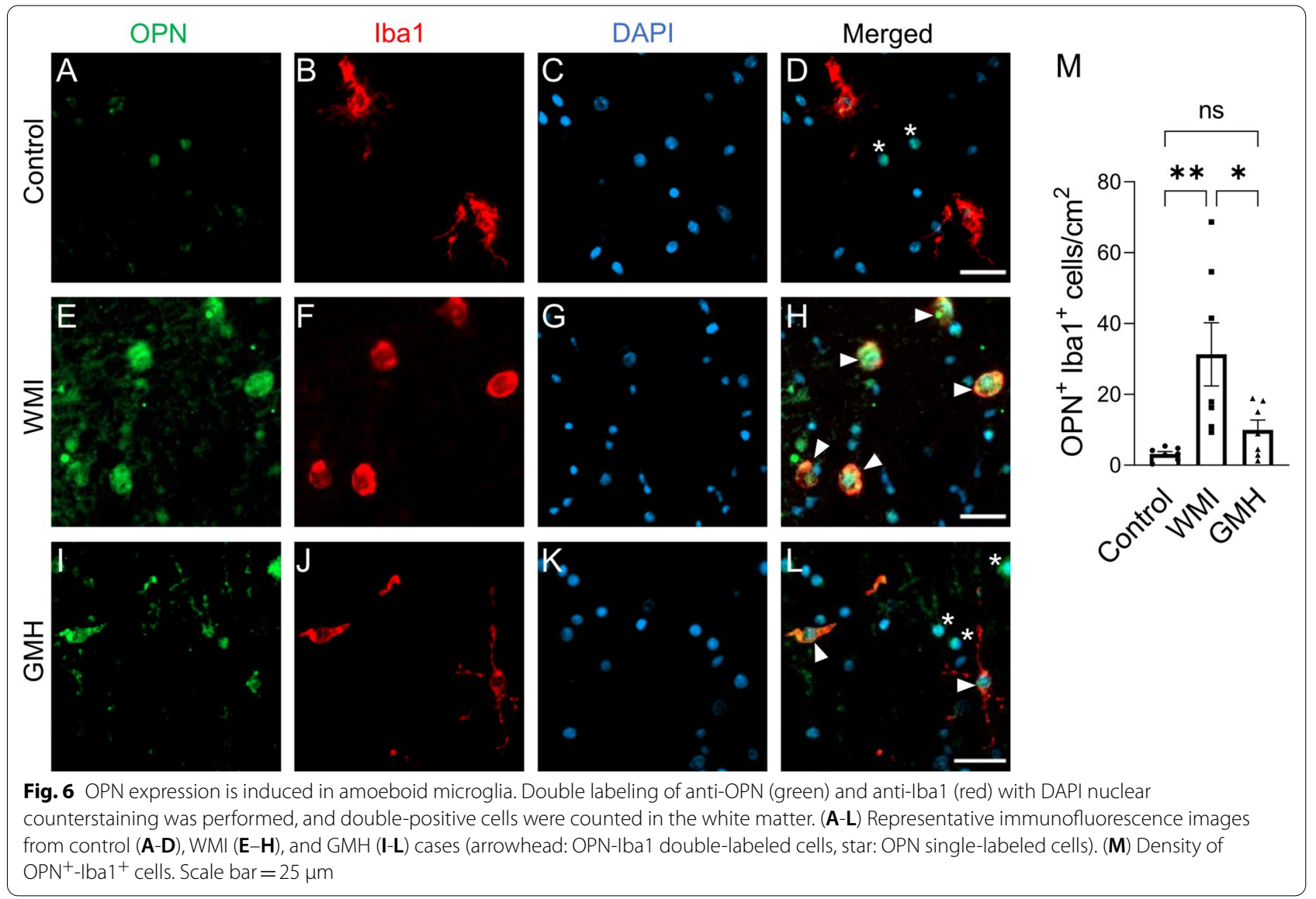



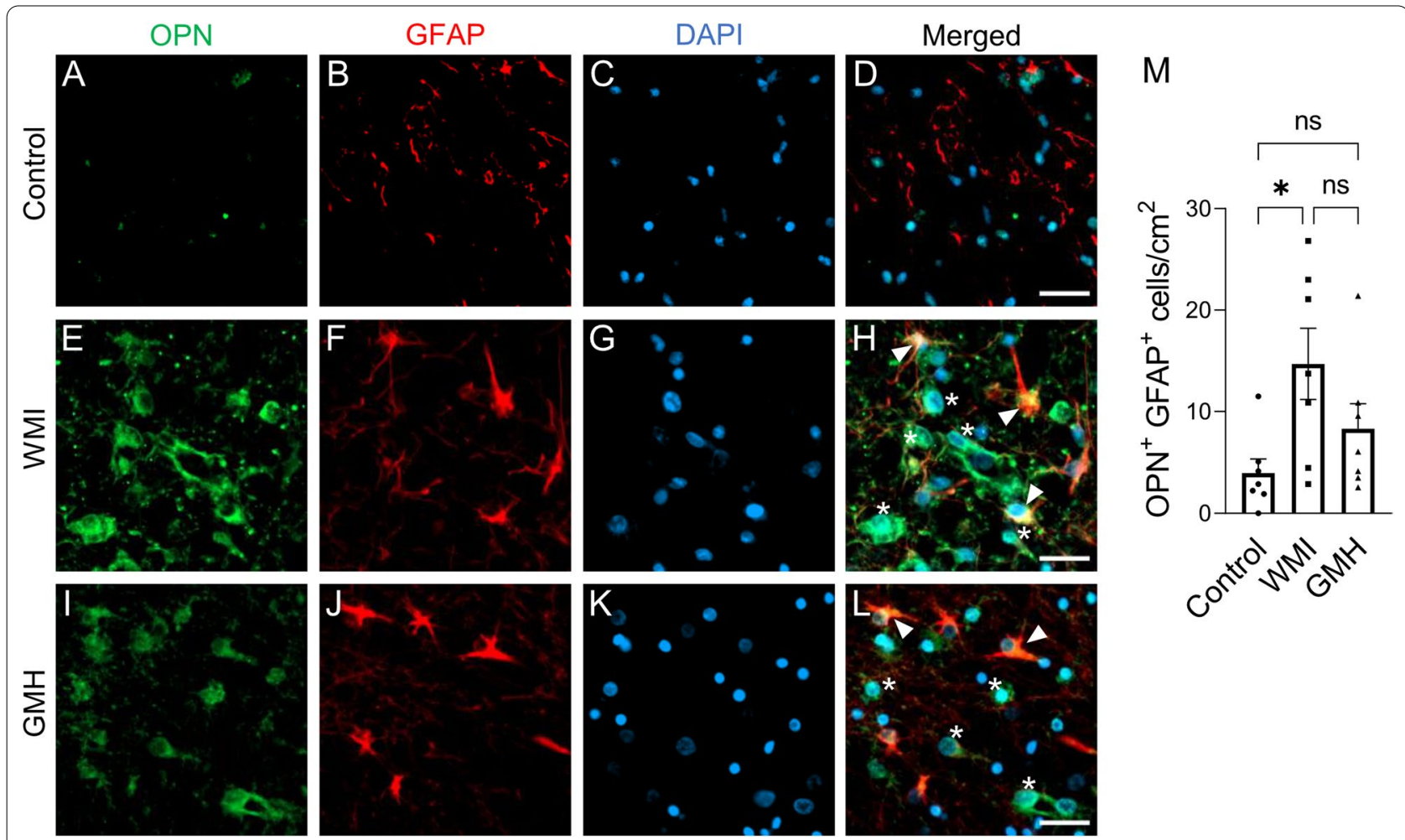

Fig. 7 Astrocytes in WMI have increased expression of OPN. Staining of anti-OPN (green) and anti-GFAP (red) with DAPI nuclear counterstaining was performed and OPN-expressing astrocytes in the white matter were counted. (A-L) Examples of OPN-GFAP double-labeled cells in control (A-D), WMI (E-H), and GMH (I-L) cases (arrowhead: OPN-GFAP double-labeled cells, star: OPN single-labeled cells). (M) Density of OPN ${ }^{+}-G_{A P}+$ cells. Scale bar $=25 \mu \mathrm{m}$

\section{Discussion}

In this study we show for the first time that the brain injury-induced increase in OPN expression in preterm infants is restricted to regions of WMI and is predominately seen in amoeboid microglia and astrocytes. In contrast, elevated OPN expression was not associated with hemorrhagic regions (Fig. 9). In the non-injured preterm brain, we found low expression of OPN in microglia, astrocytes, and oligodendrocytes. The expression of OPN in oligodendrocytes was unchanged in WMI.

In early brain development (23-35 weeks) microglia exhibit amoeboid features, while over time they acquire an intermediate morphology with few processes and ultimately mature into ramified microglia with small cell bodies and long processes [10]. The germinal matrix contains neuronal and glial precursors and is present in the foetal brain between 8 and 36 weeks' gestation. Indeed, we observed that microglia in the germinal matrix regions displayed an amoeboid morphology irrespective of injury. Moreover, the germinal matrix was rich in microglia, as previously observed [62], and in astrocytes.

Microglia are implicated in perinatal brain injury, and one of the first cellular events in WMI in preterm infants is microglial transformation to an active amoeboid phenotype [43, 63, 71]. Via their activation, migration, phagocytosis, and expression of nitric oxide synthase, nitric oxide, and proinflammatory cytokines, they are suggested to be a contributing factor in mediating preterm brain injury $[4,24,25,62,71]$. As expected, we found a significant increase in amoeboid, supposedly activated, microglia in the injured white matter in WMI cases.

Astrocytes are associated with numerous functions during brain development, including blood brain barrier formation, synaptogenesis, neurotransmission, and metabolic regulation [60]. Mature astrocytes have many branches and fine processes, and they respond to multiple forms of brain insult, including perinatal brain injury, by changing their phenotype and morphology via reactive astrogliosis [52, 59]. Reactive astrogliosis is one of the hallmarks of WMI $[27,50]$ and is a reaction to inflammation and injury that can have both beneficial and detrimental consequences, leading to hypertrophy and in extreme cases leading to inflammation and to proliferation and scar formation at the borders of the tissue damage [59]. Like microglia activation, we found 

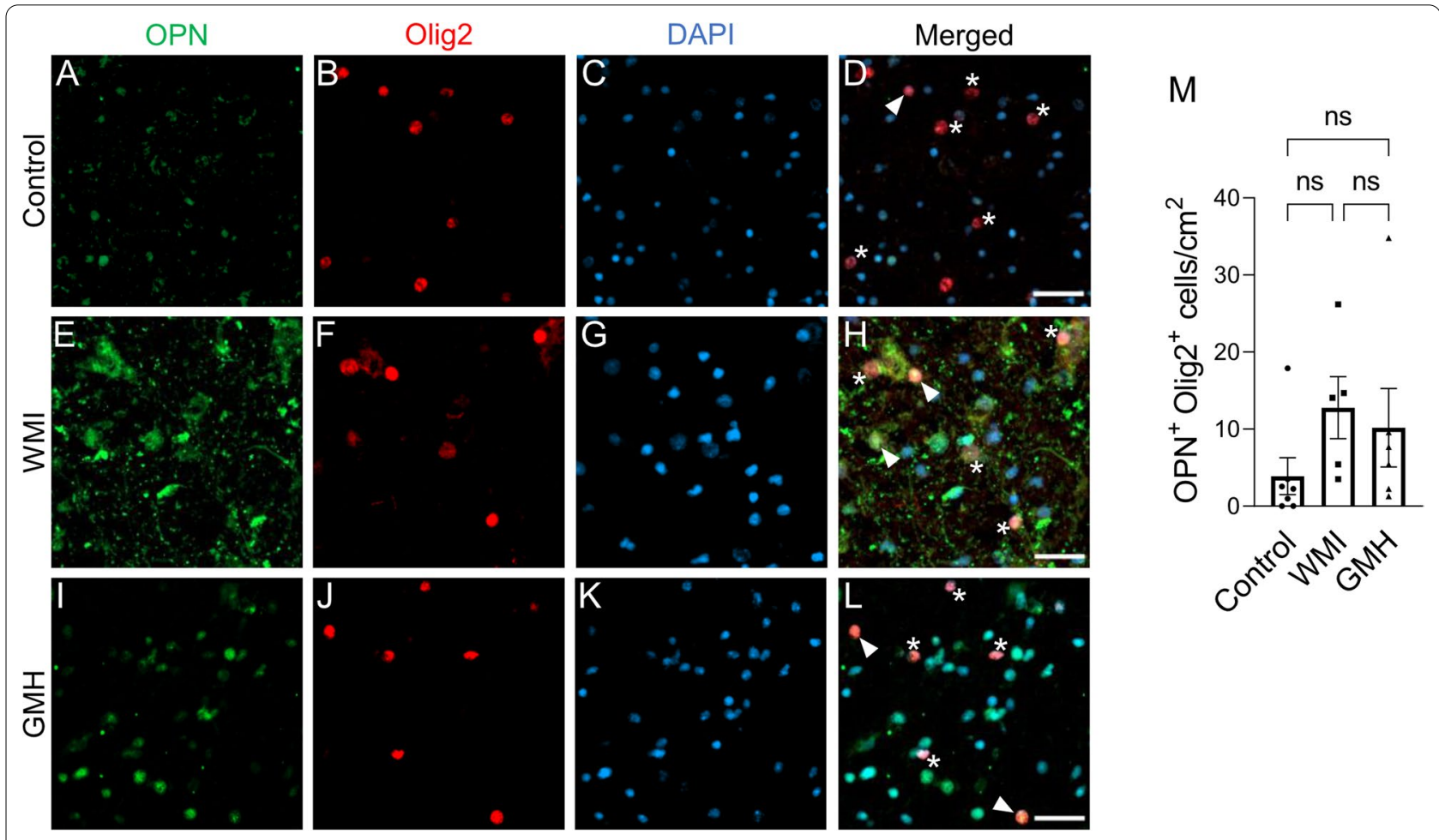

Fig. 8 OPN expression in oligodendrocytes is not increased in response to white matter injury. Oligodendrocytes were stained for anti-Olig2 (red) and anti-OPN (green) along with DAPI nuclear counterstaining, and the number of double-labeled cells in the white matter was counted. (A-L) Representative immunofluorescence images from control (A-D), WMI (E-H), and GMH (I-L) cases (arrowhead: OPN-Olig2 double-labeled cells, star: OPN single-labeled cells). (M) Density of $\mathrm{OPN}^{+}-$-Olig2 ${ }^{+}$cells. Scale bar $=25 \mu \mathrm{m}$

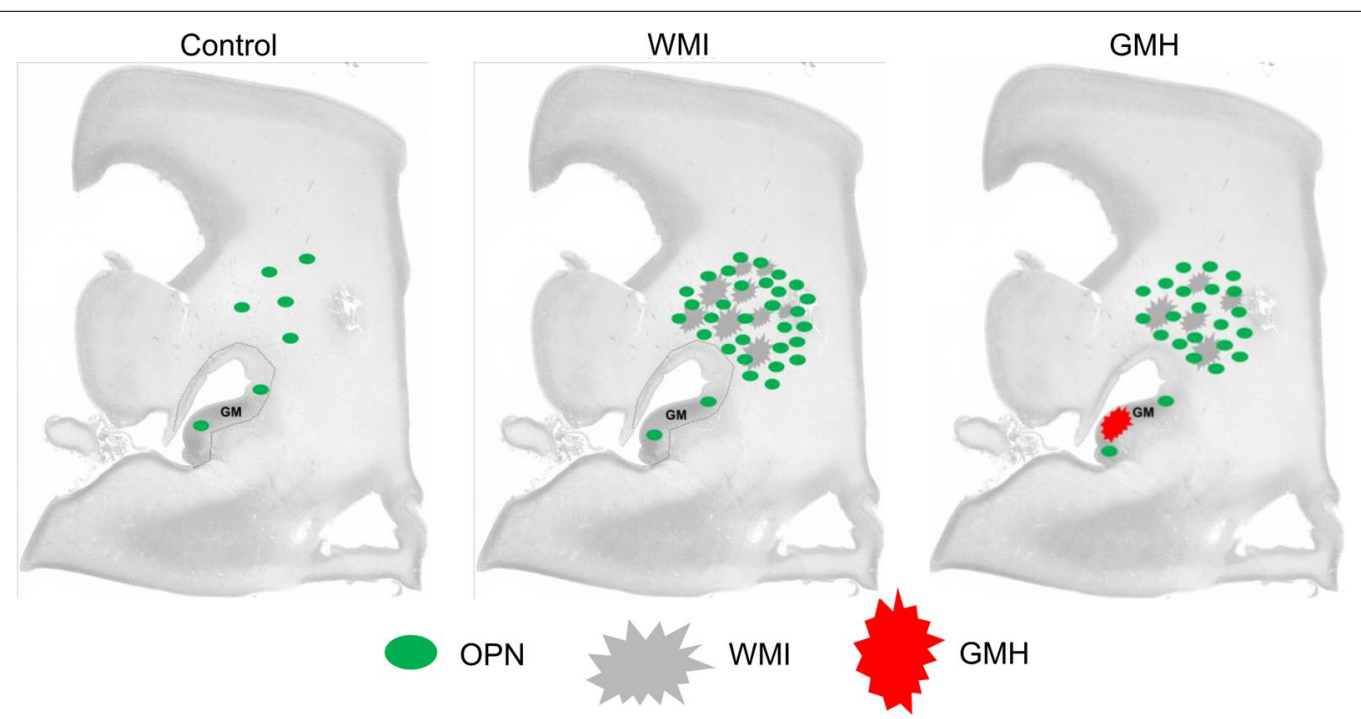

Fig. 9 Summary figure illustrating the major findings. In the non-injured developing brain, the expression of OPN is low. In preterm brain injury, the expression of OPN is elevated, and this elevation is found in the injured white matter regions but not at the site of hemorrhage in the germinal matrix regions 
manifestations of reactive astrogliosis in proximity to WMI that appeared to be linked to the severity of injury, and preterm infants with severe injury displayed an increase in astrocytes exhibiting a morphology indicating reactivity.

GMH/IVH causes blood-induced pathological reactions such that the deposition of extravasated blood in the intraventricular space, which is followed by lysis of the red blood cells resulting in a subsequent release of extracellular hemoglobin throughout the brain, including in the periventricular white matter [39]. The accumulation of blood in the cerebral ventricles of infants with IVH also damages the adjacent white matter. All together, these events induce a series of subsequent pathological processes such as oxidative stress, inflammation, pressure-induced partial ischemia, perturbed signaling pathways, and remodeling of the extracellular matrix that lead to periventricular white matter damage [9]. Indeed, autopsy studies of brain samples have revealed evidence of white matter injury in $50-78 \%$ of premature infants with IVH $[2,51,58]$. The GMH cases in the current study had various grades of hemorrhage and displayed various degrees of WMI, although the injury was generally less severe compared to WMI cases. Six out of the seven GMH cases had an infection. Moreover, GMH itself causes inflammation [3, 9, 34] together with additional complications, e.g., infection, and these are among the known factors contributing to secondary white matter brain injury in premature infants [9], which might have contributed to the upregulation of OPN expression in the white matter areas that was observed in GMH cases. Inflammation and infection are known factors that cause increased OPN expression [20, 41, 54]. Increased OPN expression in turn regulates innate immune cells (macrophages and dendritic cells) and adaptive immune cells ( $\mathrm{T}$ cells) at multiple levels (summarized and reviewed in [41]) and therefore plays an important role in the inflammatory response in multiple disease pathologies and injury processes, likely including preterm white matter injury.

Elevated OPN expression was observed in both WMI and GMH cases, and OPN immunoreactivity was restricted to the injured white matter regions. There was a significant increase in microglia expressing OPN in WMI cases, while this increase was not significant in GMH cases. This suggests that OPN is expressed predominately by microglia exhibiting an amoeboid, presumably activated phenotype, as these were more numerous in the WMI cases compared to the GMH cases. Indeed, we have previously shown that Iba1-positive microglia with amoeboid morphology are co-localized with CD68, a marker for microglia activation [33], in the periventricular white matter areas in preterm infants with $\mathrm{GMH} / \mathrm{IVH}$
[62]. The number of astrocytes expressing OPN was not significantly increased in GMH cases as it was for WMI cases, and this may reflect that there were fewer reactive astrocytes in GMH cases that also displayed less injury in the white matter compared to the WMI cases. The potential correlations between WMI severity, GMH grade, or other complications and OPN expression could not be established because of the small number of cases used in this study.

OPN expression was not elevated in hemorrhage regions, and this may indicate that only certain types of inflammation, and not extravasated blood, lead to elevated OPN expression in the brain. In addition, we did not observe OPN-positive staining in the germinal matrix regions, even though microglia in the germinal matrix displayed amoeboid morphology regardless of injury. This is different from the microglia in regions adjacent to injury in the white matter, where the majority of the OPN staining was found. Such findings suggest that elevated OPN expression is linked to WMI, and microglia activation triggered by injury type-related features, such as inflammation, rather than the phenotypic state the cells are in during specific developmental processes. Together with the finding that OPN expression in oligodendrocytes did not change after injury, this may indicate that the elevated level of OPN expression in the human preterm infant brain may play a role in inflammatory processes after WMI. Indeed, in animal models of stroke and in in vitro models, induced OPN expression in activated microglia has been demonstrated to promote phagocytosis [53, 57, 64] and to modulate cytokine expression [48]. OPN has been reported to regulate the activation and function of microglia [75], while microglia have been shown to not only be involved in inflammation, but also to be important in oligodendrocyte and white matter development as well as in regeneration of myelin [23, 40]. Further, data obtained in animal models and humans suggest that OPN plays a role in the pathogenesis of multiple sclerosis, the most common demyelinating disease $[15,17,31,55]$, and has been suggested to enhance myelin formation in vitro [55]. The finding that OPN expression in preterm infant brains is associated only with WMI may further suggest an involvement of OPN in the process of white matter damage and/or repair. Therefore, further exploring the role of OPN in CNS development, white matter injury in preterm infants, and neurodevelopmental diseases will be beneficial for increasing our knowledge of these processes to develop novel therapeutic strategies.

OPN is also induced in other cell types in the brain where it leads to subsequent microglia activation. For example, in a mouse model of ischemic stroke, regulatory $\mathrm{T}$ cell-derived OPN acts through integrin receptors 
on microglia to enhance microglial activity and promote oligodendrogenesis [56]. OPN is involved in inducing the reactivity of astrocytes and is suggested to be involved in recovery and repair $[29,49]$. In $\mathrm{OPN}^{-/-}$mice and in macrophage-depleted mice, reactive astrocytes failed to properly extend processes toward the center of the infarction in a model of photothrombotic stroke [22]. It is likely that OPN is expressed by other cell types in the injured preterm brain that were not examined in the present study, and the cellular source might be influenced by the cause or origin of injury as well as by severity or time course of injury.

In conclusion, we observed OPN expression in microglia, astrocytes, and oligodendrocytes in human preterm brains, and elevated levels of OPN in microglia and astrocytes were associated with WMI but not with hemorrhage in the germinal matrix. Our findings further suggest that OPN may take part in the inflammatory process after WMI in the preterm brain. OPN is one of the most highly regulated proteins in multiple pathological conditions, including perinatal brain injury, but its expression and cellular source in human preterm brains, and its contribution to brain injury in preterm infants, are largely unknown. This study thus facilitates our understanding of OPN's role under both physiological and pathological conditions in the human brain, and this may lead to greater elucidation of disease mechanisms and potentially better treatment strategies.

\section{Abbreviations \\ OPN: Osteopontin; WMI: White matter injury; PVWMI: Periventricular white matter injury; GMH: Germinal matrix hemorrhage; GMH-IVH: Germinal matrix- intraventricular hemorrhage; CNS: Central nervous system; H\&E: Hematoxylin and eosin; PBS: Phosphate-buffered saline; ABC: Avidin-biotin complex; DAB: 3,3'-Diamino-benzidine; ROI: Region of interest; Iba1: Ionized calcium-binding adapter molecule 1; GFAP: Glial fibrillary acidic protein.}

\section{Acknowledgements}

We gratefully acknowledge the families that consented to participate in this study. We thank Dr. Evonne Chin-Smith from Wellcome ESPRC Centre for Medical Engineering, King's College London, for processing the brain samples and for assistance with the immunofluorescence and immunohistochemistry staining experiments. We thank Dr. Maryam Ardalan from Gothenburg University for help with the microscope for stereology analysis.

\section{Authors' contributions}

$X W, R V$, and GN conceptualized the study. GN and XW wrote the manuscript. $X W, R V, G N, A B, M R, C Z, C M$, and $H H$ designed the experiments. AB performed the immunofluorescence and immunohistochemistry staining experiments. GN analyzed all staining and performed the cell counting and data analysis. All authors contributed to data interpretation, critically revised the manuscript, and approved the submitted version.

\section{Funding}

Open access funding provided by University of Gothenburg. This work was supported by the Swedish Research Council (2018-02682, 2018-02667, 201901320), the Brain Foundation (FO2017-0102 to XW), the National Natural Science Foundation of China (81771418, U1704281), the National Key Research and Development Program of China (2018YFC1004604), the Department of Science and Technology of Henan Province (171100310200); Grants from the
Swedish state under the agreement between the Swedish Government and the county councils, the ALF-agreement (ALFGBG-813291, ALFGBG-717791, ALFGBG-718591), W o M Lundgren (1320-2016, 1804-2017 and 3126-2019 to GN), Castegrens minne (LA2016-0404 to GN), Goljes minne (LA2015-0255 to GN), Mary von Sydow (4617 and 3618 to GN), Åhlénstiftelsen (193054 and $\mathrm{mH} 3 \mathrm{~h} 18$ to GN), and the Elisabeth "Bollan" Lindén scholarship (to GN). For the use of human samples, we gratefully acknowledge the financial support from the Medical Research Council (MR/K006355/1) and core funding from the Wellcome/EPSRC Centre for Medical Engineering (WT203148/Z/16/Z).

\section{Availability of data and materials}

The datasets used and/or analysed during the current study available from the corresponding author on reasonable request.

\section{Declarations}

\section{Ethics approval and consent to participate}

Written informed parental consent was acquired in accordance with the National Health Services (NHS) UK guidelines, and ethical approval was obtained from the National Research Ethics Services (West London), UK (ethic number: 07/H0707/139).

\section{Competing interests}

The authors have no conflict of interest for disclosure.

\section{Author details}

${ }^{1}$ Centre of Perinatal Medicine and Health, Institute of Neuroscience and Physiology, Department of Physiology, Sahlgrenska Academy, University of Gothenburg, 40530 Gothenburg, Sweden. ${ }^{2}$ Centre for the Developing Brain, Department of Perinatal Imaging and Health, School of Biomedical Engineering and Imaging Sciences, King's College London, King's Health Partners, St Thomas'Hospital, London, UK. ${ }^{3}$ Department of Clinical Neuroscience, Center for Brain Repair and Rehabilitation, Institute of Neuroscience and Physiology, University of Gothenburg, Gothenburg, Sweden. ${ }^{4}$ Henan Key Laboratory of Child Brain Injury and Pediatric Clinical Research Center, Institute of Neuroscience and Third Affiliated Hospital of Zhengzhou University, Zhengzhou, China. ${ }^{5}$ Centre of Perinatal Medicine and Health, Institute of Clinical Sciences, Department of Obstetrics and Gynecology, Sahlgrenska Academy, Gothenburg University, 40530 Gothenburg, Sweden. ${ }^{6}$ University of Miami Brain Endowment Bank, Miami, FL 33136, USA.

Received: 6 August 2021 Accepted: 26 September 2021

Published online: 15 October 2021

\section{References}

1. Albertsson AM, Zhang X, Leavenworth J, Bi D, Nair S, Qiao L, Hagberg H, Mallard C, Cantor H, Wang X (2014) The effect of osteopontin and osteopontin-derived peptides on preterm brain injury. J Neuroinflammation 11:197. https://doi.org/10.1186/s12974-014-0197-0

2. Armstrong DL, Sauls CD, Goddard-Finegold J (1987) Neuropathologic findings in short-term survivors of intraventricular hemorrhage. Am J Dis Child 141:617-621. https://doi.org/10.1001/archpedi.1987.0446006003 5027

3. Atienza-Navarro I, Alves-Martinez P, Lubian-Lopez S, Garcia-Alloza M (2020) Germinal matrix-intraventricular hemorrhage of the preterm newborn and preclinical models: inflammatory considerations. Int J Mol Sci. https://doi.org/10.3390/ijms21218343

4. Baburamani AA, Supramaniam VG, Hagberg H, Mallard C (2014) Microglia toxicity in preterm brain injury. Reprod Toxicol 48:106-112. https://doi. org/10.1016/j.reprotox.2014.04.002

5. Back SA (2017) White matter injury in the preterm infant: pathology and mechanisms. Acta Neuropathol 134:331-349. https://doi.org/10.1007/ s00401-017-1718-6

6. Back SA, Craig A, Kayton RJ, Luo NL, Meshul CK, Allcock N, Fern R (2007) Hypoxia-ischemia preferentially triggers glutamate depletion from oligodendroglia and axons in perinatal cerebral white matter. J Cerebral Blood Flow metabol Offic J Int Soc Cerebral Blood Flow Metabol 27:334-347. https://doi.org/10.1038/sj.jcbfm.9600344 
7. Ballabh P (2010) Intraventricular Hemorrhage in premature infants: mechanism of disease. Pediatr Res 67:1-8

8. Ballabh P (2014) Pathogenesis and prevention of intraventricular hemorrhage. Clin Perinatol 41:47-67. https://doi.org/10.1016/j.clp.2013.09.007

9. Ballabh $P$, de Vries LS (2021) White matter injury in infants with intraventricular haemorrhage: mechanisms and therapies. Nat Rev Neurol 17:199-214. https://doi.org/10.1038/s41582-020-00447-8

10. Billiards SS, Haynes RL, Folkerth RD, Trachtenberg FL, Liu LG, Volpe JJ, Kinney HC (2006) Development of microglia in the cerebral white matter of the human fetus and infant. J Comp Neurol 497:199-208. https://doi.org/ 10.1002/cne.20991

11. Boche D, Perry VH, Nicoll JAR (2013) Review: Activation patterns of microglia and their identification in the human brain. Neuropath Appl Neuro 39:3-18. https://doi.org/10.1111/nan.12011

12. Braitch M, Constantinescu CS (2010) The role of osteopontin in experimental autoimmune encephalomyelitis (EAE) and multiple sclerosis (MS). Inflamm Allergy Drug Targets 9:249-256. https://doi.org/10.2174/18715 2810793358778

13. Cantor H, Shinohara ML (2009) Regulation of T-helper-cell lineage development by osteopontin: the inside story. Nat Rev Immunol 9:137-141. https://doi.org/10.1038/nri2460

14. Cappellano G, Vecchio D, Magistrelli L, Clemente N, Raineri D, Barbero Mazzucca C, Virgilio E, Dianzani U, Chiocchetti A, Comi C (2021) The YinYang of osteopontin in nervous system diseases: damage versus repair. Neural Regen Res 16:1131-1137. https://doi.org/10.4103/1673-5374. 300328

15. Chabas D, Baranzini SE, Mitchell D, Bernard CC, Rittling SR, Denhardt DT, Sobel RA, Lock C, Karpuj M, Pedotti R et al (2001) The influence of the proinflammatory cytokine, osteopontin, on autoimmune demyelinating disease. Science 294:1731-1735. https://doi.org/10.1126/science.1062960

16. Chen W, Ma Q, Suzuki H, Hartman R, Tang J, Zhang JH (2011) Osteopontin reduced hypoxia-ischemia neonatal brain injury by suppression of apoptosis in a rat pup model. Stroke 42:764-769. https://doi.org/10.1161/ STROKEAHA.110.599118

17. Clemente N, Comi C, Raineri D, Cappellano G, Vecchio D, Orilieri E, Gigliotti CL, Boggio E, Dianzani C, Sorosina M et al (2017) Role of anti-osteopontin antibodies in multiple sclerosis and experimental Autoimmune Encephalomyelitis. Front Immunol 8:321. https://doi.org/10.3389/fimmu. 2017.00321

18. Comi C, Carecchio M, Chiocchetti A, Nicola S, Galimberti D, Fenoglio C, Cappellano G, Monaco F, Scarpini E, Dianzani U (2010) Osteopontin is increased in the cerebrospinal fluid of patients with Alzheimer's disease and its levels correlate with cognitive decline. J Alzheimers Dis 19:1143-1148. https://doi.org/10.3233/JAD-2010-1309

19. Counsell SJ, Allsop JM, Harrison MC, Larkman DJ, Kennea NL, Kapellou O, Cowan FM, Hajnal JV, Edwards AD, Rutherford MA (2003) Diffusionweighted imaging of the brain in preterm infants with focal and diffuse white matter abnormality. Pediatrics 112:1-7. https://doi.org/10.1542/ peds.112.1.1

20. Denhardt DT, Noda M, O'Regan AW, Pavlin D, Berman JS (2001) Osteopontin as a means to cope with environmental insults: regulation of inflammation, tissue remodeling, and cell survival. J Clin Investig 107:1055-1061. https://doi.org/10.1172/JCI12980

21. Ellison JA, Velier JJ, Spera P, Jonak ZL, Wang X, Barone FC, Feuerstein GZ (1998) Osteopontin and its integrin receptor alpha(v)beta3 are upregulated during formation of the glial scar after focal stroke. Stroke 29: 1698-1706; discussion 1707 Doi https://doi.org/10.1161/01.str.29.8.1698

22. Gliem M, Krammes K, Liaw L, van Rooijen N, Hartung HP, Jander S (2015) Macrophage-derived osteopontin induces reactive astrocyte polarization and promotes re-establishment of the blood brain barrier after ischemic stroke. Glia 63:2198-2207. https://doi.org/10.1002/glia.22885

23. Hammond TR, Dufort C, Dissing-Olesen L, Giera S, Young A, Wysoker A, Walker AJ, Gergits F, Segel M, Nemesh J et al (2019) Single-Cell RNA sequencing of microglia throughout the mouse lifespan and in the injured brain reveals complex cell-state changes. Immunity 50(253271):e256. https://doi.org/10.1016/j.immuni.2018.11.004

24. Haynes RL, Folkerth RD, Keefe RJ, Sung I, Swzeda LI, Rosenberg PA, Volpe JJ, Kinney HC (2003) Nitrosative and oxidative injury to premyelinating oligodendrocytes in periventricular leukomalacia. J Neuropath Exp Neur 62:441-450. https://doi.org/10.1093/jnen/62.5.441
25. Hedtjarn M, Leverin AL, Eriksson K, Blomgren K, Mallard C, Hagberg H (2002) Interleukin-18 involvement in hypoxic-ischemic brain injury. J Neurosci 22:5910-5919

26. Hedtjarn M, Mallard C, Hagberg H (2004) Inflammatory gene profiling in the developing mouse brain after hypoxia-ischemia. J Cerebral Blood Flow metabol Offic J Int Soc Cerebral Blood Flow Metabol 24:1333-1351. https://doi.org/10.1097/01.WCB.0000141559.17620.36

27. Hirayama A, Okoshi Y, Hachiya Y, Ozawa Y, Ito M, Kida Y, Imai Y, Kohsaka S, Takashima S (2001) Early immunohistochemical detection of axonal damage and glial activation in extremely immature brains with periventricular leukomalacia. Clin Neuropathol 20:87-91

28. Hyvarinen T, Hagman S, Ristola M, Sukki L, Veijula K, Kreutzer J, Kallio P, Narkilahti S (2019) Co-stimulation with IL-1 beta and TNF-alpha induces an inflammatory reactive astrocyte phenotype with neurosupportive characteristics in a human pluripotent stem cell model system. Sci RepUk. https://doi.org/10.1038/s41598-019-53414-9

29. Ikeshima-Kataoka H, Matsui Y, Uede T (2018) Osteopontin is indispensable for activation of astrocytes in injured mouse brain and primary culture. Neurol Res 40:1071-1079. https://doi.org/10.1080/01616412.2018.15179 95

30. Inder TE, Warfield SK, Wang H, Huppi PS, Volpe JJ (2005) Abnormal cerebral structure is present at term in premature infants. Pediatrics 115:286-294. https://doi.org/10.1542/peds.2004-0326

31. Jansson M, Panoutsakopoulou V, Baker J, Klein L, Cantor H (2002) Cutting edge: Attenuated experimental autoimmune encephalomyelitis in eta-1/ osteopontin-deficient mice. J Immunol 168:2096-2099. https://doi.org/ 10.4049/jimmunol.168.5.2096

32. Jinnai M, Koning $G$, Singh-Mallah $G$, Jonsdotter $A$, Leverin $A L$, Svedin P, Nair S, Takeda S, Wang X, Mallard C et al (2020) A model of germinal matrix hemorrhage in preterm rat pups. Front Cell Neurosci 14:535320. https://doi.org/10.3389/fncel.2020.535320

33. Jurga AM, Paleczna M, Kuter KZ (2020) Overview of general and discriminating markers of differential microglia phenotypes. Front Cell Neurosci 14:198. https://doi.org/10.3389/fncel.2020.00198

34. Klebe D, McBride D, Flores JJ, Zhang JH, Tang J (2015) Modulating the immune response towards a neuroregenerative peri-injury milieu after cerebral hemorrhage. J Neuroimmune Pharmacol 10:576-586. https:// doi.org/10.1007/s11481-015-9613-1

35. Klebermass-Schrehof K, Czaba C, Olischar M, Fuiko R, Waldhoer T, Rona Z, Pollak A, Weninger M (2012) Impact of low-grade intraventricular hemorrhage on long-term neurodevelopmental outcome in preterm infants. Childs Nerv Syst 28:2085-2092. https://doi.org/10.1007/ s00381-012-1897-3

36. Kuan CY, Roth KA, Flavell RA, Rakic P (2000) Mechanisms of programmed cell death in the developing brain. Trends Neurosci 23:291-297. https:// doi.org/10.1016/s0166-2236(00)01581-2

37. Kuban K, Sanocka U, Leviton A, Allred EN, Pagano M, Dammann O, Share J, Rosenfeld D, Abiri M, DiSalvo D et al (1999) White matter disorders of prematurity: association with intraventricular hemorrhage and ventriculomegaly. The Developmental Epidemiology Network. J Pediatr 134:539-546. https://doi.org/10.1016/s0022-3476(99)70237-4

38. Lekic T, Manaenko A, Rolland W, Krafft PR, Peters R, Hartman RE, Altay O, Tang J, Zhang JH (2012) Rodent neonatal germinal matrix hemorrhage mimics the human brain injury, neurological consequences, and posthemorrhagic hydrocephalus. Exp Neurol 236:69-78. https://doi.org/10. 1016/j.expneurol.2012.04.003

39. Ley D, Romantsik O, Vallius S, Sveinsdottir K, Sveinsdottir S, Agyemang AA, Baumgarten M, Morgelin M, Lutay N, Bruschettini M et al (2016) High presence of extracellular hemoglobin in the periventricular white matter following preterm intraventricular hemorrhage. Front Physiol. https://doi. org/10.3389/fphys.2016.00330

40. Li Q, Cheng Z, Zhou L, Darmanis S, Neff NF, Okamoto J, Gulati G, Bennett ML, Sun LO, Clarke LE et al (2019) Developmental heterogeneity of microglia and brain myeloid cells revealed by deep single-Cell RNA sequencing. Neuron 101(207-223):e210. https://doi.org/10.1016/j.neuron.2018.12. 006

41. Lund SA, Giachelli CM, Scatena M (2009) The role of osteopontin in inflammatory processes. J Cell Commun Signal 3:311-322. https://doi. org/10.1007/s12079-009-0068-0 
42. Martinez-Biarge M, Groenendaal F, Kersbergen KJ, Benders MJ, Foti F, Cowan FM, de Vries LS (2016) MRI based preterm white matter injury classification: the importance of sequential imaging in determining severity of injury. PLoS ONE 11:e0156245. https://doi.org/10.1371/journal.pone. 0156245

43. McNamara NB, Miron VE (2020) Microglia in developing white matter and perinatal brain injury. Neurosci Lett 714:134539. https://doi.org/10.1016/j. neulet.2019.134539

44. Melero-Jerez C, Fernandez-Gomez B, Lebron-Galan R, Ortega MC, Sanchez-de Lara I, Ojalvo AC, Clemente D, de Castro F (2021) Myeloidderived suppressor cells support remyelination in a murine model of multiple sclerosis by promoting oligodendrocyte precursor cell survival, proliferation, and differentiation. Glia 69:905-924. https://doi.org/10. 1002/glia.23936

45. Meller R, Stevens SL, Minami M, Cameron JA, King S, Rosenzweig H, Doyle K, Lessov NS, Simon RP, Stenzel-Poore MP (2005) Neuroprotection by osteopontin in stroke. J Cerebral Blood Flow metabol Offic J Int Soc Cerebral Blood Flow Metabol 25:217-225. https://doi.org/10.1038/sj.jcbfm. 9600022

46. Oka A, Belliveau MJ, Rosenberg PA, Volpe JJ (1993) Vulnerability of oligodendroglia to glutamate: pharmacology, mechanisms, and prevention. J Neurosci 13:1441-1453

47. Parodi A, Govaert P, Horsch S, Bravo MC, Ramenghi LA, eur USbg, (2020) Cranial ultrasound findings in preterm germinal matrix haemorrhage, sequelae and outcome. Pediatr Res 87:13-24. https://doi.org/10.1038/ s41390-020-0780-2

48. Rabenstein M, Vay SU, Flitsch LJ, Fink GR, Schroeter M, Rueger MA (2016) Osteopontin directly modulates cytokine expression of primary microglia and increases their survival. J Neuroimmunol 299:130-138. https://doi. org/10.1016/j.jneuroim.2016.09.009

49. Riew TR, Kim S, Jin X, Kim HL, Lee JH, Lee MY (2019) Osteopontin and its spatiotemporal relationship with glial cells in the striatum of rats treated with mitochondrial toxin 3-nitropropionic acid: possible involvement in phagocytosis. J Neuroinflammation 16:99. https://doi.org/10.1186/ s12974-019-1489-1

50. Roessmann U, Gambetti P (1986) Pathological reaction of astrocytes in perinatal brain injury - immunohistochemical study. Acta Neuropathol 70:302-307. https://doi.org/10.1007/Bf00686088

51. Rushton DI, Preston PR, Durbin GM (1985) Structure and evolution of echo dense lesions in the neonatal brain. A combined ultrasound and necropsy study. Arch Dis Child 60:798-808. https://doi.org/10.1136/adc. 60.9.798

52. Salmaso N, Jablonska B, Scafidi J, Vaccarino FM, Gallo V (2014) Neurobiology of premature brain injury. Nat Neurosci 17:341-346. https://doi.org/ 10.1038/nn.3604

53. Schack L, Stapulionis R, Christensen B, Kofod-Olsen E, Sorensen UBS, Vorup-Jensen T, Sorensen ES, Hollsberg P (2009) Osteopontin enhances phagocytosis through a novel osteopontin receptor, the alpha(x)beta(2) Integrin. J Immunol 182:6943-6950. https://doi.org/10.4049/jimmunol. 0900065

54. Scott JA, Weir ML, Wilson SM, Xuan JW, Chambers AF, McCormack DG (1998) Osteopontin inhibits inducible nitric oxide synthase activity in rat vascular tissue. Am J Physiol 275:H2258-2265. https://doi.org/10.1152/ ajpheart.1998.275.6.H2258

55. Selvaraju R, Bernasconi L, Losberger C, Graber P, Kadi L, Avellana-Adalid V, Picard-Riera N, Baron Van Evercooren A, Cirillo R, Kosco-Vilbois M et al (2004) Osteopontin is upregulated during in vivo demyelination and remyelination and enhances myelin formation in vitro. Mol Cell Neurosci 25:707-721. https://doi.org/10.1016/j.mcn.2003.12.014

56. Shi L, Sun Z, Su W, Xu F, Xie D, Zhang Q, Dai X, lyer K, Hitchens TK, Foley LM et al. (2021) Treg cell-derived osteopontin promotes microglia-mediated white matter repair after ischemic stroke. Immunity, https://doi.org/ 10.1016/j.immuni.2021.04.022

57. Shin YJ, Kim HL, Choi JS, Choi JY, Cha JH, Lee MY (2011) Osteopontin: correlation with phagocytosis by brain macrophages in a rat model of stroke. Glia 59:413-423. https://doi.org/10.1002/glia.21110

58. Skullerud K, Westre B (1986) Frequency and prognostic significance of germinal matrix hemorrhage, periventricular leukomalacia, and pontosubicular necrosis in preterm neonates. Acta Neuropathol 70:257-261. https://doi.org/10.1007/BF00686080
59. Sofroniew MV (2009) Molecular dissection of reactive astrogliosis and glial scar formation. Trends Neurosci 32:638-647. https://doi.org/10. 1016/j.tins.2009.08.002

60. Sofroniew MV, Vinters HV (2010) Astrocytes: biology and pathology. Acta Neuropathol 119:7-35. https://doi.org/10.1007/s00401-009-0619-8

61. Stoll BJ, Hansen NI, Bell EF, Walsh MC, Carlo WA, Shankaran S, Laptook AR, Sanchez PJ, Van Meurs KP, Wyckoff M et al (2015) Trends in care practices, morbidity, and mortality of extremely preterm neonates, 1993-2012. JAMA 314:1039-1051. https://doi.org/10.1001/jama.2015.10244

62. Supramaniam V, Vontell R, Srinivasan L, Wyatt-Ashmead J, Hagberg H, Rutherford M (2013) Microglia activation in the extremely preterm human brain. Pediatr Res 73:301-309. https://doi.org/10.1038/pr.2012. 186

63. Tahraoui SL, Marret S, Bodenant C, Leroux P, Dommergues MA, Evrard P, Gressens $P$ (2001) Central role of microglia in neonatal excitotoxic lesions ef the murine periventricular white matter. Brain Pathol 11:56-71

64. Tambuyzer BR, Casteleyn C, Vergauwen H, Van Cruchten S, Van Ginneken C (2012) Osteopontin alters the functional profile of porcine microglia in vitro. Cell Biol Int 36:1233-1238. https://doi.org/10.1042/Cbi20120172

65. Tanaka F, Ozawa Y, Inage Y, Deguchi K, Itoh M, Imai Y, Kohsaka S, Takashima S (2000) Association of osteopontin with ischemic axonal death in periventricular leukomalacia. Acta Neuropathol 100:69-74. https://doi.org/10.1007/s004010051194

66. Torres-Platas SG, Comeau S, Rachalski A, Dal Bo G, Cruceanu C, Turecki G, Giros B, Mechawar N (2014) Morphometric characterization of microglial phenotypes in human cerebral cortex. J Neuroinflammation. https://doi. org/10.1186/1742-2094-11-12

67. van Tilborg E, de Theije CGM, van Hal M, Wagenaar N, de Vries LS, Benders MJ, Rowitch DH, Nijboer CH (2018) Origin and dynamics of oligodendrocytes in the developing brain: Implications for perinatal white matter injury. Glia 66:221-238. https://doi.org/10.1002/glia.23256

68. van Velthoven CT, Heijnen CJ, van Bel F, Kavelaars A (2011) Osteopontin enhances endogenous repair after neonatal hypoxic-ischemic brain injury. Stroke 42:2294-2301. https://doi.org/10.1161/STROKEAHA.110. 608315

69. Wang J, Huang J, Zhu M, Chen S, Chen C, Miao C, He H, Song Y (2019) Osteopontin potentiates PM-induced IL-1alpha and IL-1 beta production via the ERK/JNK signaling pathway. Ecotoxicol Environ Saf 171:467-474. https://doi.org/10.1016/j.ecoenv.2019.01.005

70. Wang KX, Denhardt DT (2008) Osteopontin: role in immune regulation and stress responses. Cytokine Growth Factor Rev 19:333-345. https:// doi.org/10.1016/j.cytogfr.2008.08.001

71. Verney C, Pogledic I, Biran V, Adle-Biassette H, Fallet-Bianco C, Gressens P (2012) Microglial reaction in axonal crossroads is a hallmark of noncystic periventricular white matter injury in very preterm infants. J Neuropath Exp Neur 71:251-264. https://doi.org/10.1097/NEN.0b013e3182496429

72. Volpe JJ (2019) Dysmaturation of premature brain: importance, cellular mechanisms, and potential interventions. Pediatr Neurol 95:42-66. https://doi.org/10.1016/j.pediatrneurol.2019.02.016

73. Vontell R, Supramaniam V, Thornton C, Wyatt-Ashmead J, Mallard C, Gressens P, Rutherford M, Hagberg H (2013) Toll-like receptor 3 expression in glia and neurons alters in response to white matter injury in preterm infants. Dev Neurosci 35:130-139. https://doi.org/10.1159/000346158

74. Vontell R, Supramaniam V, Wyatt-Ashmead J, Gressens P, Rutherford M, Hagberg H, Thornton C (2015) Cellular mechanisms of toll-like receptor-3 activation in the thalamus are associated with white matter injury in the developing brain. J Neuropathol Exp Neurol 74:273-285. https://doi.org/ 10.1097/NEN.0000000000000172

75. Yu H, Liu XH, Zhong YS (2017) The effect of osteopontin on microglia. Biomed Res Int. https://doi.org/10.1155/2017/1879437

76. Zhao C, Fancy SP, Ffrench-Constant C, Franklin RJ (2008) Osteopontin is extensively expressed by macrophages following CNS demyelination but has a redundant role in remyelination. Neurobiol Dis 31: 209-217 https:// doi.org/10.1016/j.nbd.2008.04.

\section{Publisher's Note}

Springer Nature remains neutral with regard to jurisdictional claims in published maps and institutional affiliations. 